\title{
A REFINED SOLUTION TO CLASSICAL UNIT COMMITMENT PROBLEM USING IWO ALGORITHM
}

\author{
C. Christober Asir Rajan ${ }^{1}$, K. Surendra' ${ }^{2}$ B. Rama Anvesh Reddy ${ }^{3}$, R. Shobana ${ }^{4}$, Y. Sreekanth $\operatorname{Reddy}^{5}$ \\ ${ }^{1}$ Associate Professor, Electrical and Electronics Engineering, Pondicherry Engineering College, Pondicherry, India \\ ${ }^{2}$ Student, Electrical and Electronics Engineering, Pondicherry Engineering College, Pondicherry, India \\ ${ }^{3}$ Student, Electrical and Electronics Engineering, Pondicherry Engineering College, Pondicherry, India \\ ${ }^{4}$ Student, Electrical and Electronics Engineering, Pondicherry Engineering College, Pondicherry, India \\ ${ }^{5}$ Student, Electrical and Electronics Engineering, Pondicherry Engineering College, Pondicherry, India
}

\begin{abstract}
This paper proposes a solution to effectively determine Unit Commitment and generation cost using the technique of Invasive Weed Optimization (IWO).The objective of this paper is to find the generation scheduling such that the total operating cost can be minimized, when subjected to variety of constraints. This also means that finding the optimal generating unit commitment in the power system for the next $H$ hours is desirable. The different constraints considered in this technique are the time constraint and spinning reserve constraint. The result obtained from this is to be compared with the already existing result of Particle Swarm Optimization (PSO) for an 8 hour 4 unit IEEE system and 24 hour 10 unit IEEE system.
\end{abstract}

Keywords: constraints, fuel cost, Iwo, optimization.

\section{INTRODUCTION}

The power systems operation decision functions has three stages. The first stage consists of the long-term where variables like capacity, type and number of power generators are determined. The second stage is to decide how to meet the excepted load during each hour and based on the generators operating costs and constraints. This decision is termed as Unit Commitment, takes place between one day and a few days ahead of the actual operations. The third stage is to efficiently determine the amount of power each committed unit will produce to meet the real-time electricity demand. This decision is called Economic load dispatch.

Unit Commitment is an Optimization problem used to determine the operation schedule of the generating units at every hour interval with varying loads under different constraints. The importance of UC is increasing with the constantly varying demands so there is an urgent need in the power sector to keep track of the latest methodologies to optimize the cost function. The optimal generation of power is necessary to meet the load demand and also to avoid wastage of power (Allen.J. Wood and B.F. Wollenberg(1984)). The different methods to effectively bring down the cost of generation are called evolutionary algorithms, meta-heuristic algorithms which are based on generic population. Some of them being Bacterial Foraging Technique, Particle Swam method, Cuckoo search method and Firefly algorithms. All these techniques are mapped from real life events such as growth of bacteria, foraging behavior of honeybees, nesting of birds. All these methods are known to give out the optimum cost of power generation over a scheduled period of time depending on the load requirements, assuming that all the generator units are $\mathrm{ON}$.

\section{UC METHODOLOGY}

UCP formulation for a large generating system results in a large scale non-linear mixed integer program with typically thousands of binary and continuous variables. A variety of techniques such as Lagrangian relaxation, dynamic programming, branch and bound, network programming and Benders decomposition along with meta-heuristics has been used to solve the UCP. Out of all different solution methods employed for this Lagrangian relaxation (LR) is the most widely used method because of its success in solving large scale problems. The LR method is used to find out the unit commitment results for a particular duration. The objective function of LR is to find out the units that are the most economical for operation. The economics of operation depend upon the fuel cost, uptime, downtime, cold time, maximum and minimum generation limits. The fuel cost of a generation unit is given in the form of a second order polynomial function which depends on the power output of that particular unit.

$$
F(i)=a_{i} P_{i}^{2}+b_{i} P_{i}+c_{i}
$$

Where,

$F(i)$ - fuel cost of the unit i

$P_{i}$ - Power output of the unit i 
$a_{i}, b_{i}, c_{i}$ - coefficients of the fuel cost polynomial

LR method finds out the derivative of the polynomial function $F(i)$ and obtains the incremental cost of the unit $\chi$, lambda. This $\chi$ gives us the idea of the units with the least operational cost. The units are arranged in the order of increasing incremental cost starting with the one that has the least $\chi$. The different conditions considered for determining the unit commitment are

1. Uptime

2. Downtime

3. Cold time

4. Initial status

5. Maximum generation limit

6. Minimum generation limit

7. Spinning reserve

\section{INVASIVE WEED OPTIMIZATION}

The technique of IWO was inspired from the biological growth of weed plants. It was first used by Mehrabian and Lucas in solving control system designing. This technique is based on the colonizing behavior of weed plants. Weed plants are called invasive because of the growth of weed plants is extensively invading in the growth area. IWO is known to be highly converging in nature since it is a derivative free algorithm. It also converges to the optimal solution thereby eliminating the possibilities of sub optimal solutions. This integer coded algorithm also involves simple coding. IWO has been so far implemented for several applications like DNA computing, antenna system design.

In this algorithm, the number of decision variables are taken in the form of seeds and then randomly distributed in a definite search space. These seeds are then allowed to grow into plants and the fitness of each individual plant is determined. Depending upon the fitness values, new seeds are generated by each plant in accordance with a normalized standard deviation $\square$. The importance of this $\square$ is that it helps in converging to the optimal solution faster as it determines exactly where to distribute the new seeds so that the seeds always approach the optimal solution. In the next step the combined fitness values of seeds and plants is calculated until the fitness value converges to an optimal solution. The objective function of this technique is similar to any method,

Min FC total $=\sum F C i$

Subjected to the constraints,

- $\quad$ Equality Constraint

$$
\square P_{i}=P_{d}
$$

- Inequality Constraint

$P i \min \square P i \square P i \max$
- $\quad$ Time Based Constraints

$$
\begin{gathered}
\left(T_{\text {on }}(i, t-1)-T_{u p}(i)\right)(U(i, t-1)-U(i, t)) \square 0 \\
\left(T d o w n(i)-T_{\text {off }}(i, t-1)\right)(U(i, t-1)-U(i, t)) \square \\
\text { Ramp Based Constraints } \\
P(i, t)-P(i, t-1) \square U R(i) \\
P(i, t-1)-P(i, t) \square D R(i) \\
\text { Spinning Reserve } \\
\mathrm{n} \quad I(i, t) r_{s}(i, t) \square R_{s}(i, t)
\end{gathered}
$$

\section{Step 1:}

Read the input from the Unit commitment matrix and assign a matric of size depending upon the units that are ON.

\section{Step 2:}

Randomize the values obtained for generation for each unit subjected to the constraints time, ramp and spinning reserve. These units, otherwise called as seeds assume random values in the search space. The search space is reduced in this method as compared to the traditional IWO which assumes that all units are $\mathrm{ON}$.

\section{Step 3:}

Determine the fuel cost for the obtained combination of generation values and repeat this procedure for a total of 100 iterations. The fuel cost, otherwise called as fitness values are assigned to the respective seeds.

\section{Step 4:}

Arrange these values of fuel cost in the increasing order. The minimum amount serves as the best fitness value.

Now depending upon these fitness values the next generation of seeds is produced using zero mean and variable standard deviation spread over the entire field.

\section{Step 5:}

The procedure is repeated until the maximum number of iterations is not met. The values with the best fitness values are taken and are put forwards as the generation values provided they are within the individual generation limits and meet the demand requirements. 


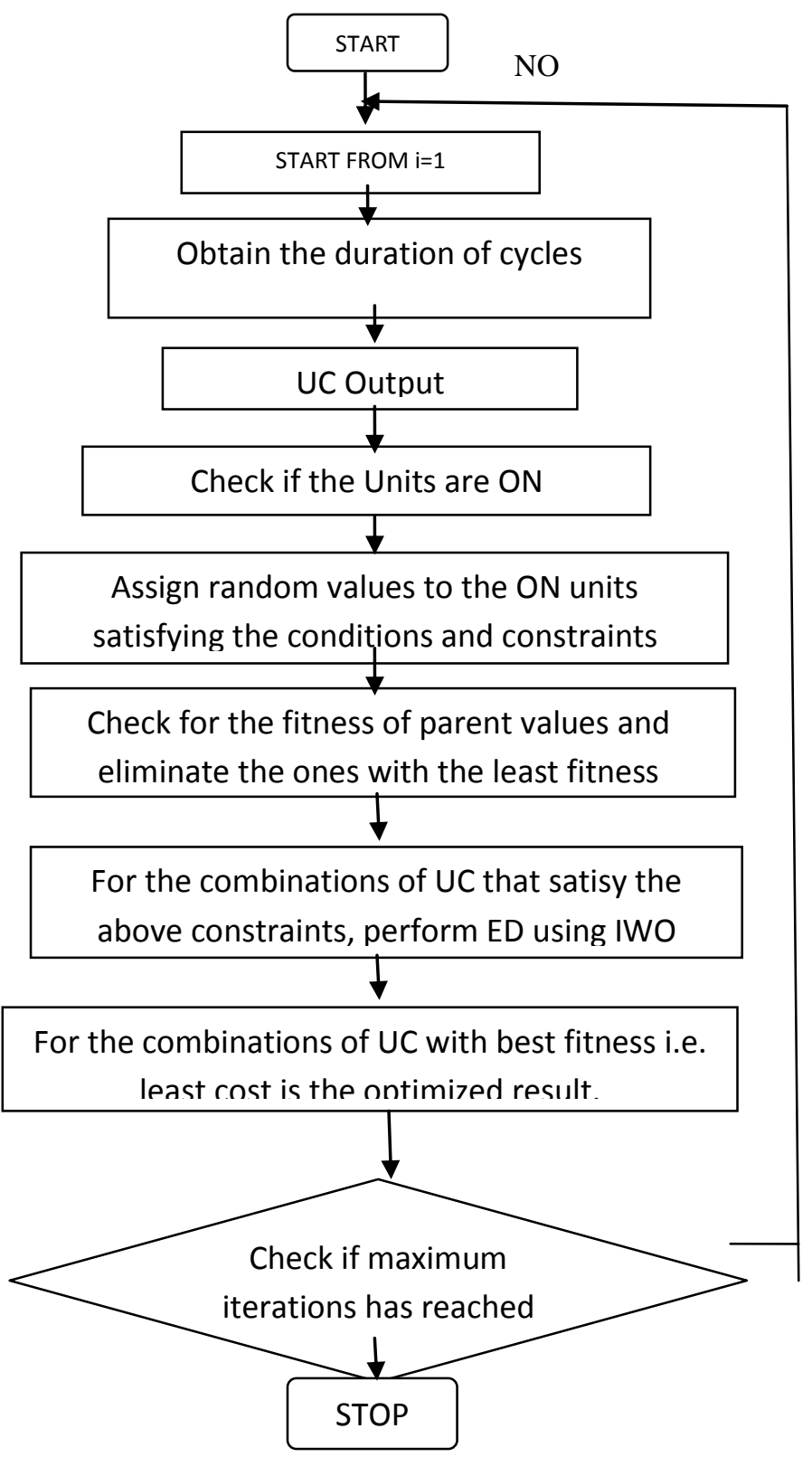

\section{RESULTS AND DISCUSSION}

The developed algorithm was tested with 4 Unit 8 hour system and 10 Unit 24 Hour system. The detailed analysis are listed in the following tables.

\section{IEEE CASE STUDY 1: FOUR UNITS EIGHT HOUR} SYSTEM

In this four unit eight hour system, Table-1 the system input data and load demand is given. The unit commitment scheduling of all the four generators for 8 hours is given in Table-2. In Table-3 the generation dispatch using IWO is listed for each hour and the same is compared with PSO. The total cost of IWO is reasonably less when compared to PSO. The same is represented in the form of a graph in Fig.2 where the generation cost of every hour using IWO and PSO has been shown. Fig.3 shows the convergence graph for the IEEE system.

IEEE CASE STUDY 2: TEN UNITS TWENTY FOUR HOUR SYSTEM

Similar to the first case study, a second analysis was performed on a ten unit 24 hour system. In this case study, in Table-4 the system input data and load data is given. The unit commitment scheduling of all 10 generators for 24 hours is given in Table-5. In Table-6 the generation dispatch using IWO is listed for each hour. The total cost of IWO is reasonably less when compared to PSO. The same is represented in the form of a graph in Fig.4 where the generation cost of every hour using IWO and PSO has been shown. Fig.5 shows the convergence graph for the IEEE system.

Fig.1 Flowchart for UC using IWO algorithm

Table-1 System Input Data

\begin{tabular}{|c|c|c|c|c|c|c|c|c|c|c|c|}
\hline Unit & $\begin{array}{c}\text { Pma x } \\
(\mathbf{M W})\end{array}$ & $\begin{array}{l}\text { Pmin } \\
(\mathbf{M W})\end{array}$ & $\begin{array}{c}\mathbf{c} \\
\mathbf{( \$ / h r})\end{array}$ & $\begin{array}{c}\mathbf{b} \\
\mathbf{( \$ / M W} \\
\mathbf{h r})\end{array}$ & $\begin{array}{c}\mathbf{a} \\
\mathbf{( \$ \mathbf { M W }} \mathbf{2} \mathbf{h})\end{array}$ & $\begin{array}{l}\mathbf{t u p} \\
\mathbf{( h r})\end{array}$ & $\begin{array}{c}\text { tdown } \\
\mathbf{( h r})\end{array}$ & $\begin{array}{c}\text { tcold } \\
\mathbf{( h r})\end{array}$ & $\begin{array}{l}\text { Shr } \\
\mathbf{( \$ )}\end{array}$ & $\begin{array}{c}\text { Scr } \\
\mathbf{( \$ )}\end{array}$ & $\begin{array}{c}\text { Init. } \\
\text { Status }\end{array}$ \\
\hline $\mathbf{1}$ & 300 & 75 & $\begin{array}{c}684.7 \\
4\end{array}$ & 16.83 & 0.0021 & 5 & 4 & 5 & 500 & 1100 & 8 \\
\hline $\mathbf{2}$ & 250 & 60 & 585.6 & 16.95 & 0.0042 & 5 & 3 & 5 & 170 & 400 & 8 \\
\hline $\mathbf{3}$ & 80 & 25 & 213 & 20.74 & 0.0018 & 4 & 2 & 4 & 150 & 350 & -5 \\
\hline $\mathbf{4}$ & 60 & 20 & 252 & 23.6 & 0.0034 & 1 & 1 & 0 & 0 & 0.02 & -6 \\
\hline
\end{tabular}




\section{LOAD DEMAND}

\begin{tabular}{|c|l|c|c|c|c|c|c|c|}
\hline Time (hr) & $\mathbf{1}$ & $\mathbf{2}$ & $\mathbf{3}$ & $\mathbf{4}$ & $\mathbf{5}$ & $\mathbf{6}$ & $\mathbf{7}$ & $\mathbf{8}$ \\
\hline $\begin{array}{c}\text { Load } \\
\text { (MW) }\end{array}$ & 450 & 530 & 600 & 540 & 400 & 280 & 290 & 500 \\
\hline
\end{tabular}

Table-2 Units on/off status

\begin{tabular}{|c|c|c|c|c|}
\hline Unit/Time(hr) & $\mathbf{1}$ & $\mathbf{2}$ & $\mathbf{3}$ & $\mathbf{4}$ \\
\hline $\mathbf{1}$ & 1 & 1 & 0 & 0 \\
\hline $\mathbf{2}$ & 1 & 1 & 0 & 0 \\
\hline $\mathbf{3}$ & 1 & 1 & 1 & 0 \\
\hline $\mathbf{4}$ & 1 & 1 & 1 & 0 \\
\hline $\mathbf{5}$ & 1 & 1 & 0 & 0 \\
\hline $\mathbf{6}$ & 1 & 1 & 0 & 0 \\
\hline $\mathbf{7}$ & 1 & 1 & 0 & 0 \\
\hline $\mathbf{8}$ & 1 & 1 & 0 & 0 \\
\hline
\end{tabular}

Table-3: Generation Dispatch

\begin{tabular}{|c|c|c|c|c|c|c|c|c|c|c|c|}
\hline $\begin{array}{c}\text { Time } \\
(\mathrm{hrs})\end{array}$ & \multicolumn{2}{c|}{$\begin{array}{c}\text { UNIT I } \\
(\mathrm{MW})\end{array}$} & \multicolumn{2}{c|}{$\begin{array}{c}\text { UNIT II } \\
(\mathrm{MW})\end{array}$} & \multicolumn{2}{c|}{$\begin{array}{c}\text { UNIT III } \\
(\mathrm{MW})\end{array}$} & $\begin{array}{c}\text { UNIT IV } \\
(\mathrm{MW})\end{array}$ & $\begin{array}{c}\text { LOAD } \\
(\mathrm{MW})\end{array}$ & \multicolumn{2}{c|}{$\begin{array}{c}\text { COST/hr } \\
(\$ / \mathrm{hr})\end{array}$} \\
\hline & PSO & IWO & PSO & IWO & PSO & IWO & PSO & IWO & & PSO & IWO \\
\hline 1 & 292.86 & 300 & 132.14 & 150 & 25 & 0 & 0 & 0 & 450 & 9575 & 9145.36 \\
\hline 2 & 300 & 300 & 205 & 230 & 25 & 0 & 0 & 0 & 530 & 10892 & 10629.04 \\
\hline 3 & 300 & 300 & 250 & 250 & 30 & 50 & 20 & 0 & 600 & 12571 & 12262.86 \\
\hline 4 & 300 & 300 & 215 & 215 & 25 & 25 & 0 & 0 & 540 & 11079 & 11079.38 \\
\hline 5 & 276.19 & 276 & 123.81 & 124 & 0 & 0 & 0 & 0 & 400 & 8241.8 & 8241.8 \\
\hline 6 & 196.19 & 196 & 83.81 & 84 & 0 & 0 & 0 & 0 & 280 & 6103.1 & 6103.1 \\
\hline 7 & 202.86 & 203 & 87.143 & 87 & 0 & 0 & 0 & 0 & 290 & 6279.8 & 6279.8 \\
\hline 8 & 300 & 300 & 200 & 200 & 0 & 0 & 0 & 0 & 500 & 10066 & 10066 \\
\hline
\end{tabular}




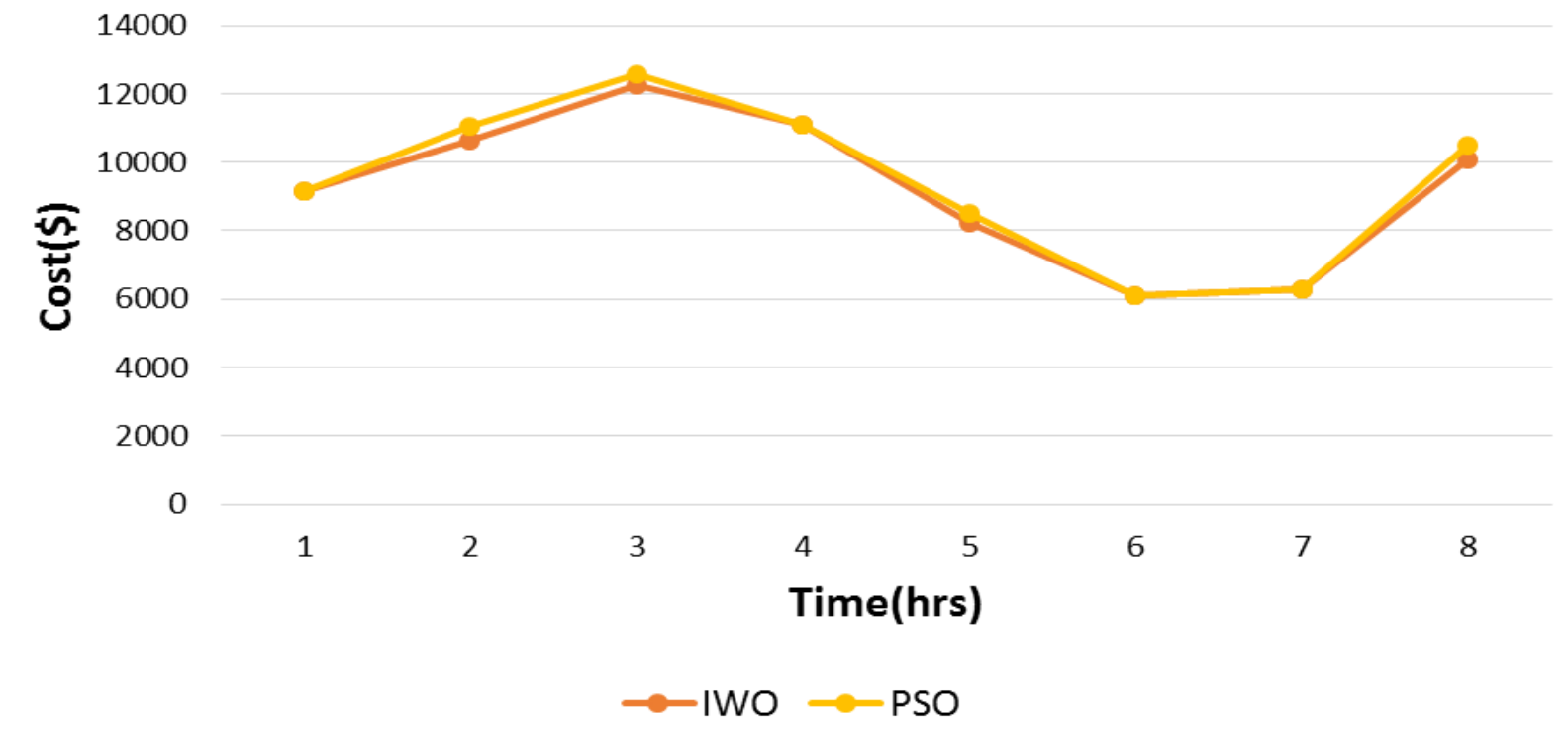

Fig.2 comparison of IWO and PSO for 4 units 8 hour system

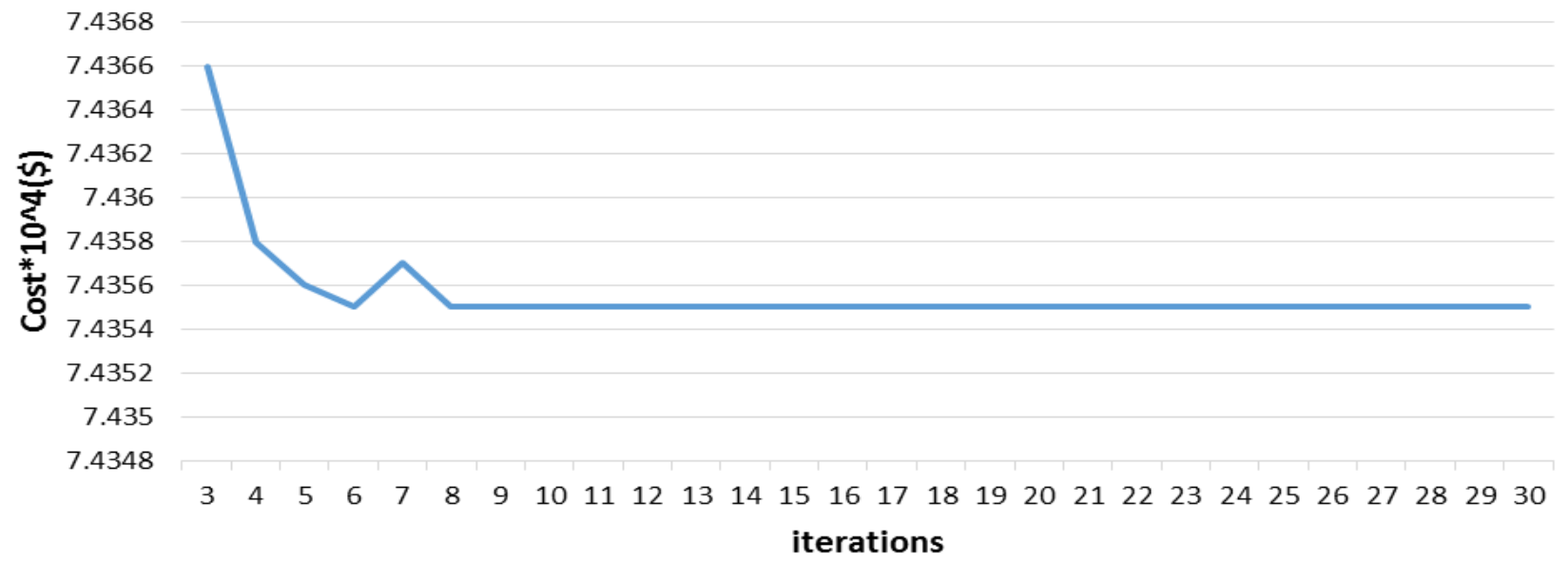

Fig.3 Convergence graph for an 4 unit 8 hour system by using IWO algorithm

Table-4 system input data for 10 unit 24 hour IEEE system

\begin{tabular}{|c|c|c|c|c|c|c|c|c|c|c|c|}
\hline UNIT & $\begin{array}{l}\text { Pmax } \\
\text { (MW) }\end{array}$ & $\begin{array}{l}\text { Pmin } \\
\text { (MW) }\end{array}$ & $\begin{array}{l}\text { C } \\
(\$ / h r)\end{array}$ & $\begin{array}{l}\text { b } \\
(\$ / M W h \\
\text { r) }\end{array}$ & $\begin{array}{l}\text { A } \\
\left(\$ / \mathbf{M W}^{2}\right. \\
\text { h) }\end{array}$ & $\begin{array}{l}\text { Tup } \\
\text { (hr) }\end{array}$ & $\begin{array}{l}\text { Tdown } \\
\text { (hr) }\end{array}$ & $\begin{array}{l}\text { Tcold } \\
\text { (hr) }\end{array}$ & $\begin{array}{l}\text { Shr } \\
\text { (\$) }\end{array}$ & $\begin{array}{l}\text { Scr } \\
(\$)\end{array}$ & $\begin{array}{l}\text { Init. } \\
\text { Status }\end{array}$ \\
\hline 1 & 455 & 150 & 1000 & 16.19 & 0.00048 & 8 & 8 & 5 & 4500 & 9000 & 8 \\
\hline 2 & 455 & 150 & 970 & 17.26 & 0.00031 & 8 & 8 & 5 & 5000 & 10000 & 8 \\
\hline 3 & 130 & 20 & 700 & 16.6 & 0.002 & 5 & 5 & 4 & 550 & 1100 & -5 \\
\hline 4 & 130 & 20 & 680 & 16.5 & 0.00211 & 5 & 5 & 4 & 560 & 1120 & -5 \\
\hline 5 & 162 & 25 & 450 & 19.7 & 0.00398 & 6 & 6 & 4 & 900 & 1800 & -6 \\
\hline 6 & 80 & 20 & 370 & 22.26 & 0.00712 & 3 & 3 & 2 & 170 & 340 & -3 \\
\hline 7 & 85 & 25 & 480 & 27.74 & 0.00079 & 3 & 3 & 2 & 260 & 520 & -3 \\
\hline 8 & 55 & 10 & 660 & 25.92 & 0.00413 & 1 & 1 & 0 & 30 & 60 & -1 \\
\hline 9 & 55 & 10 & 665 & 27.27 & 0.00222 & 1 & 1 & 0 & 30 & 60 & -1 \\
\hline 10 & 55 & 10 & 670 & 22.79 & 0.00173 & 1 & 1 & 0 & 30 & 60 & -1 \\
\hline
\end{tabular}




\section{LOAD DEMAND}

\begin{tabular}{|l|l|l|l|l|l|l|l|l|l|l|l|l|}
\hline Time (hr) & 1 & 2 & 3 & 4 & 5 & 6 & 7 & 8 & 9 & 10 & 11 & 12 \\
\hline Load (MW) & 700 & 750 & 850 & 950 & 1000 & 1100 & 1150 & 1200 & 1300 & 1400 & 1450 & 1500 \\
\hline Time (hr) & 13 & 14 & 15 & 16 & 17 & 18 & 19 & 20 & 21 & 22 & 23 & 24 \\
\hline Load (MW) & 1400 & 1300 & 1200 & 1050 & 1000 & 1100 & 1200 & 1400 & 1300 & 1100 & 900 & 800 \\
\hline
\end{tabular}

Table-6 Units on/off status

\begin{tabular}{|c|c|c|c|c|c|c|c|c|c|c|}
\hline Unit/Time(hr) & $\mathbf{1}$ & $\mathbf{2}$ & $\mathbf{3}$ & $\mathbf{4}$ & $\mathbf{5}$ & $\mathbf{6}$ & $\mathbf{7}$ & $\mathbf{8}$ & $\mathbf{9}$ & $\mathbf{1 0}$ \\
\hline $\mathbf{1}$ & 1 & 1 & 0 & 0 & 0 & 0 & 0 & 0 & 0 & 0 \\
\hline $\mathbf{2}$ & 1 & 1 & 0 & 0 & 0 & 0 & 0 & 0 & 0 & 0 \\
\hline $\mathbf{3}$ & 1 & 1 & 0 & 0 & 0 & 0 & 0 & 0 & 0 & 0 \\
\hline $\mathbf{4}$ & 1 & 1 & 0 & 1 & 0 & 0 & 0 & 0 & 0 & 0 \\
\hline $\mathbf{5}$ & 1 & 1 & 0 & 1 & 1 & 0 & 0 & 0 & 0 & 0 \\
\hline $\mathbf{6}$ & 1 & 1 & 0 & 1 & 1 & 0 & 0 & 0 & 0 & 0 \\
\hline $\mathbf{7}$ & 1 & 1 & 0 & 1 & 1 & 0 & 0 & 0 & 0 & 0 \\
\hline $\mathbf{8}$ & 1 & 1 & 1 & 1 & 1 & 0 & 0 & 0 & 0 & 0 \\
\hline $\mathbf{9}$ & 1 & 1 & 1 & 1 & 1 & 1 & 0 & 0 & 0 & 0 \\
\hline $\mathbf{1 0}$ & 1 & 1 & 1 & 1 & 1 & 1 & 1 & 0 & 0 & 0 \\
\hline $\mathbf{1 1}$ & 1 & 1 & 1 & 1 & 1 & 1 & 1 & 1 & 0 & 0 \\
\hline $\mathbf{1 2}$ & 1 & 1 & 1 & 1 & 1 & 1 & 1 & 1 & 1 & 0 \\
\hline $\mathbf{1 3}$ & 1 & 1 & 1 & 1 & 1 & 1 & 1 & 0 & 0 & 0 \\
\hline $\mathbf{1 4}$ & 1 & 1 & 1 & 1 & 1 & 1 & 0 & 0 & 0 & 0 \\
\hline $\mathbf{1 5}$ & 1 & 1 & 1 & 1 & 1 & 0 & 0 & 0 & 0 & 0 \\
\hline $\mathbf{1 6}$ & 1 & 1 & 1 & 1 & 1 & 0 & 0 & 0 & 0 & 0 \\
\hline $\mathbf{1 7}$ & 1 & 1 & 1 & 1 & 1 & 0 & 0 & 0 & 0 & 0 \\
\hline $\mathbf{1 8}$ & 1 & 1 & 1 & 1 & 1 & 0 & 0 & 0 & 0 & 0 \\
\hline $\mathbf{1 9}$ & 1 & 1 & 1 & 1 & 1 & 1 & 0 & 0 & 0 & 0 \\
\hline $\mathbf{2 0}$ & 1 & 1 & 1 & 1 & 1 & 1 & 0 & 1 & 1 & 0 \\
\hline $\mathbf{2 1}$ & 1 & 1 & 1 & 1 & 1 & 1 & 0 & 0 & 0 & 0 \\
\hline $\mathbf{2 2}$ & 1 & 1 & & 1 & 0 & 0 & 0 & 0 & 0 & 0 \\
\hline $\mathbf{2 3}$ & 1 & 1 & 0 & 0 & 0 & 0 & 0 & 0 & 0 & 0 \\
\hline $\mathbf{2 4}$ & 1 & 1 & 0 & 0 & 0 & 0 & 0 & 0 & 0 & 0 \\
\hline
\end{tabular}

Table-7: Generation Dispatch

\begin{tabular}{|l|l|l|l|l|l|l|l|l|l|l|l|l|}
\hline Time & load & $\mathbf{1}$ & $\mathbf{2}$ & $\mathbf{3}$ & $\mathbf{4}$ & $\mathbf{5}$ & $\mathbf{6}$ & $\mathbf{7}$ & $\mathbf{8}$ & $\mathbf{9}$ & $\mathbf{1 0}$ & $\mathbf{C o s t}(\mathbf{\$} / \mathbf{h r})$ \\
\hline $\mathbf{1}$ & 700 & 455 & 245 & 0 & 0 & 0 & 0 & 0 & 0 & 0 & 0 & 13683.129 \\
\hline $\mathbf{2}$ & 750 & 455 & 295 & 0 & 0 & 0 & 0 & 0 & 0 & 0 & 0 & 14554.499 \\
\hline $\mathbf{3}$ & 850 & 455 & 395 & 0 & 0 & 0 & 0 & 0 & 0 & 0 & 0 & 16301.889 \\
\hline $\mathbf{4}$ & 950 & 455 & 365 & 0 & 130 & 0 & 0 & 0 & 0 & 0 & 0 & 18658.511 \\
\hline $\mathbf{5}$ & 1000 & 455 & 424 & 0 & 96 & 25 & 0 & 0 & 0 & 0 & 0 & 20022.81 \\
\hline $\mathbf{6}$ & 1100 & 455 & 455 & 0 & 130 & 60 & 0 & 0 & 0 & 0 & 0 & 21863.109 \\
\hline $\mathbf{7}$ & 1150 & 455 & 455 & 0 & 130 & 110 & 0 & 0 & 0 & 0 & 0 & 22881.947 \\
\hline $\mathbf{8}$ & 1200 & 455 & 455 & 130 & 130 & 30 & 0 & 0 & 0 & 0 & 0 & 24153.171 \\
\hline $\mathbf{9}$ & 1300 & 455 & 455 & 130 & 130 & 110 & 20 & 0 & 0 & 0 & 0 & 26591.787 \\
\hline $\mathbf{1 0}$ & 1400 & 455 & 455 & 130 & 130 & 162 & 43 & 0 & 0 & 0 & 0 & 29368.73 \\
\hline $\mathbf{1 1}$ & 1450 & 455 & 455 & 130 & 130 & 162 & 80 & 0 & 0 & 0 & 0 & 31227.683 \\
\hline $\mathbf{1 2}$ & 1500 & 455 & 455 & 130 & 130 & 162 & 80 & 0 & 0 & 0 & 0 & 33204.01 \\
\hline $\mathbf{1 3}$ & 1400 & 455 & 455 & 130 & 130 & 162 & 43 & 25 & 0 & 0 & 0 & 29368.73 \\
\hline
\end{tabular}




\begin{tabular}{|l|l|l|l|l|l|l|l|l|l|l|l|l|}
\hline $\mathbf{1 4}$ & 1300 & 455 & 455 & 130 & 130 & 110 & 20 & 25 & 13 & 0 & 0 & 26581.787 \\
\hline $\mathbf{1 5}$ & 1200 & 455 & 455 & 130 & 130 & 30 & 0 & 42 & 36 & 10 & 0 & 24153.171 \\
\hline $\mathbf{1 6}$ & 1050 & 455 & 322 & 126 & 122 & 25 & 0 & 25 & 0 & 0 & 0 & 21547.438 \\
\hline $\mathbf{1 7}$ & 1000 & 455 & 384 & 74 & 62 & 25 & 0 & 0 & 0 & 0 & 0 & 20657.692 \\
\hline $\mathbf{1 8}$ & 1100 & 455 & 376 & 114 & 130 & 25 & 0 & 0 & 0 & 0 & 0 & 22393.052 \\
\hline $\mathbf{1 9}$ & 1200 & 455 & 455 & 130 & 115 & 25 & 20 & 0 & 0 & 0 & 0 & 24615.266 \\
\hline $\mathbf{2 0}$ & 1400 & 455 & 455 & 130 & 130 & 159 & 51 & 0 & 10 & 10 & 0 & 30166.773 \\
\hline $\mathbf{2 1}$ & 1300 & 455 & 455 & 130 & 130 & 110 & 20 & 0 & 0 & 0 & 0 & 26591.787 \\
\hline $\mathbf{2 2}$ & 1100 & 455 & 385 & 130 & 130 & 0 & 0 & 0 & 0 & 0 & 0 & 21882.161 \\
\hline $\mathbf{2 3}$ & 900 & 455 & 445 & 0 & 0 & 0 & 0 & 0 & 0 & 0 & 0 & 17180.909 \\
\hline $\mathbf{2 4}$ & 800 & 455 & 345 & 0 & 0 & 0 & 0 & 0 & 0 & 0 & 0 & 15430.419 \\
\hline & & & & & & & & & & & Total & 553081.46 \\
\hline
\end{tabular}
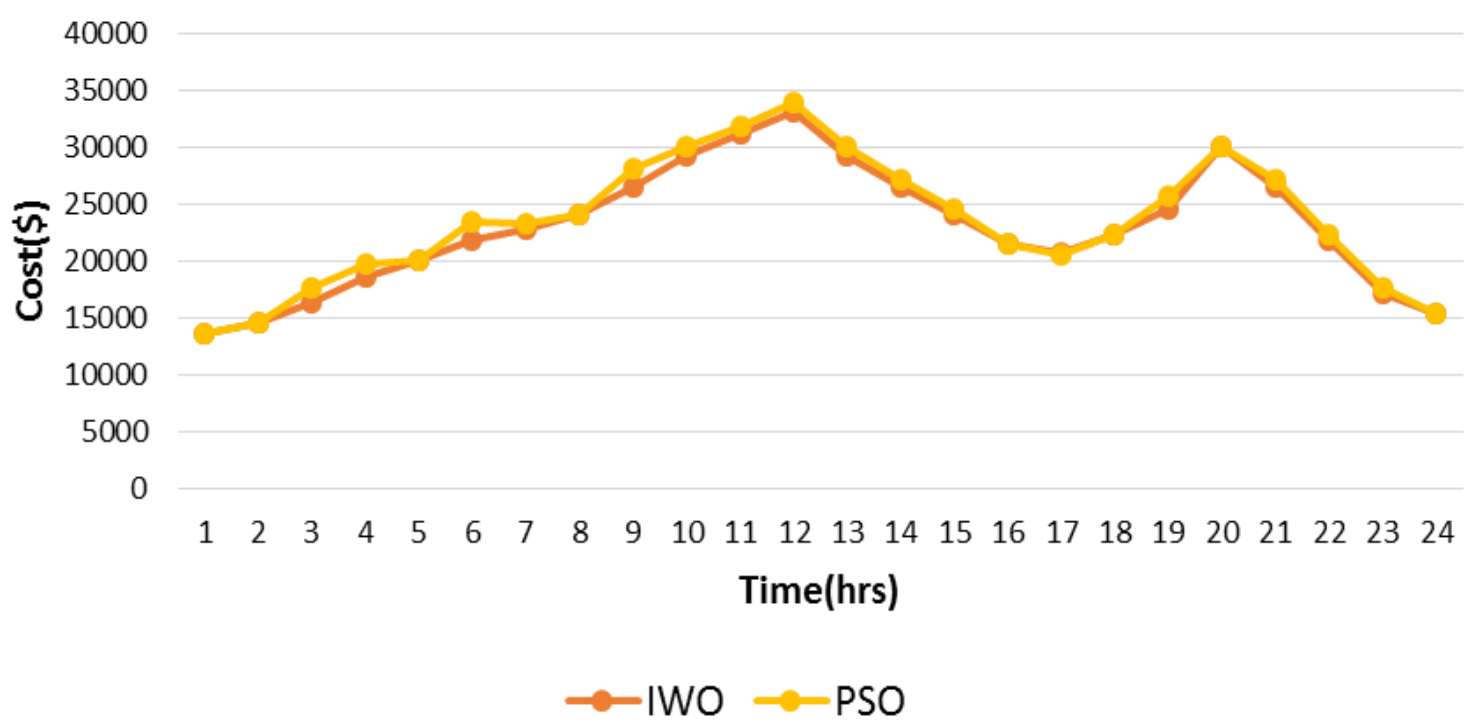

Fig.4 comparison of IWO and PSO for 10 unit 24 hour system

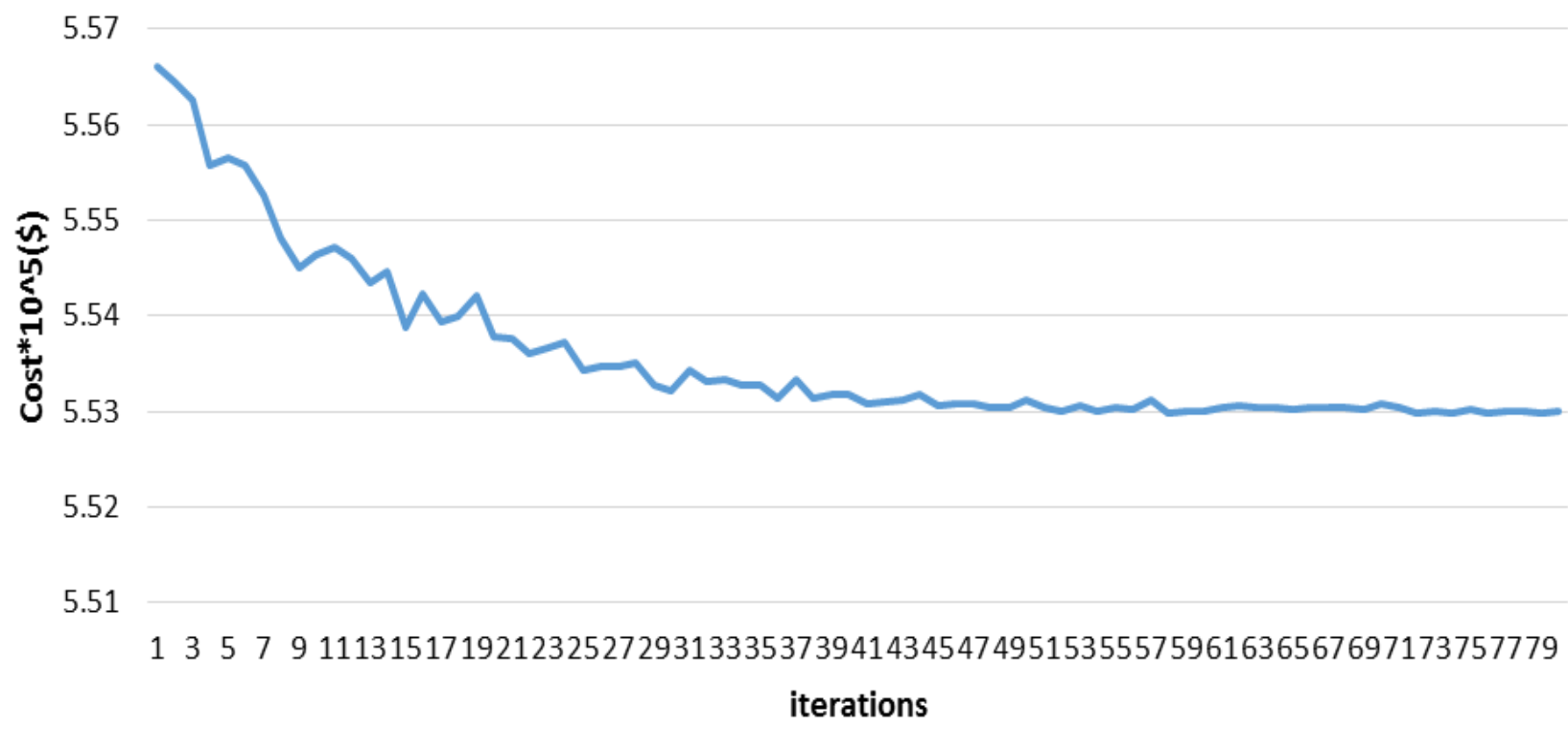

Fig.5 convergence graph for an 10 unit 24 hour system by using IWO algorithm 


\section{CONCLUSIONS}

This paper proposes an improved variant of a recently developed ecologically inspired algorithm called Invasive Weed Optimization, for finding the solution to classical unit commitment problem. This paper evidently proves that the IWO technique is much more effective than PSO in case of cost optimization for generating power. The inputs are taken in the form of Unit Commitment data obtained by LR method which effectively reduces time of execution along with giving more optimized results. This technique could be extended for any number of generating units and for any duration of load scheduling. Future works could rely on the possibilities of obtaining Unit Commitment output using the

Invasive Weed Optimization technique itself instead of obtaining the outputs of Unit Commitment from some other technique which will effectively reduce the speed of execution using the invasive weed optimization technique. The area of applications of IWO is vast. This technique could also be employed in distribution of power in the transmission system. Obtaining data for optimized transmission of power flow using IWO could lead to a completely optimized power grid, right from generation of power to distribution to the consumers.

\section{REFERENCES}

[1] A.J. Wood and F. Wollenberg "Power generation, operation and Control".

[2] M. Shaheri-Ardakani, M. Rshanaei, A. Rahimi-Kian, C. Lucas, " $\quad$ A study of electricity market dynamics using Invasive Weed Colonization Optimization," in Proc.IEEE Symp. Comput.Intell.Gmes, 2008.

[3] H. Sepehri Rad, C. Lucas," A Recommender System based on Invasive Weed Optimization Algorithm", IEEE Congress on Evolutionary Computation, CEC 2007.

[4] S. Karimkashi, Ahmed A. Kishk, “ Invasive Weed Optimization and its Features in Electromagnetics", IEEE Transcations on Antenna and Propogation.

[5] Narayana Prasadh Padhy "Unit Commitment- A bibiliographical survey".

[6] R. Sharma, Niranjan Nayak, Krishnanand K.R, P.K.Rout, "Modifies Invasive Weed Optimization with dual mutation technique for dynamic economic dispatch", 1998.

[7] A.R. Mehrabian, C. Lucas, A novel Numerical Optimization Algorithm Inspired from Weed Colonization, Ecological Informatics, 2006.

[8] Lee FN, Breipohl A M. "Reserve constrained economic Dispatch with prohibited operating zones." IEEE Transaction on Power Systems, 1993, 8(1):246-254

[9] Fan J Y, McDonald J D. "A practical approach to real time economic dispatch considering units prohibited operating zones." IEEE Transactions on Power Systems, 1994,9(4):1737-1743

[10] Orero S O, Irving M R. "Economic dispatch of generators with prohibited operating zones: a genetic algorithm approach." IEEE Proceedings.Generation, Transmission and Distribution,1996,143(6):529-534

[11] Jayabarathi T, Sadasivam G, Ramachandran V. "Evolutionary programming based economic dispatch of generators with prohibited operating zones." Electrical Power Sysyems Research, 1999,52(3):261266

[12] Liang Z X,Glover J D. “A zoom feature for a dynamic programming solution to economic dispatch including transmission losses." IEEE Transactions on Power Systems, 1992, 7(2):544-550

[13] Yang X S, Hosseini S SS, Gandomi A H. “ Firefly algorithm for solving non-convex economic dispatch problems with valve loading effect." Applied Soft Computing, 2010,12(3):1180-1186

[14] Jeyakumar D N, Jayabarathi T, Raghunathan $\mathrm{T}$. "Particle Swarm Optimization for various types of economic dispatch problems." International Journal of Electrical Power \& Energy Sysyems, 2006,28(1):36-42

[15] Sinha N, Chakrabarti R, Chattopadhyay $\mathrm{P}$ K. "Evolutionary programming techniques for economic load dispatch." IEEE Transactions on Evolutionary Computation, 2003,7(1):83-94.

[16] T. Logenthiran, " Formulation of Unit Commitment (UC) P roblems and Analysis of available Methodologies Used for Solving the Problems", IEEE ICSET 2010.

\section{NOMENCLATURE}

F(i) Fuel cost- objective function.

P(i) Power output of the generation unit.

$\mathrm{J}^{*} \quad$ Objective function value of the optimal solution to the primal problem

$\mathrm{P}_{d} \quad$ Load requirements

$\mathrm{P}_{\max }$ Maximum amount of power unit can produce once it is turned on

$\mathrm{P}_{\text {min }}$ Minimum amount of power unit can produce once it is turned on

$\mathrm{P}_{k t} \quad$ Power produced by unit $\mathrm{k}$ at time period $\mathrm{t}$

$\mathrm{S}_{c} \quad$ Cold state startup cost.

$\mathrm{S}_{h} \quad$ Hot state startup cost.

$\mathrm{S}_{k t} \quad$ Cost of starting up unit $\mathrm{k}$ at time $\mathrm{t}$.

$\mathrm{t}_{\text {coldstar }}$ Time a generator is in hot state after it is turned off

$\mathrm{t}_{u p} \quad$ Minimum number of hours required for a generator to stay up once it is on

$\mathrm{t}_{\text {down }}$ Minimum number of hours required for a generator to stay down once it is off.

$\lambda$ Incremental cost.

$\sigma$ Standard deviation of the load at hour $\mathrm{t}$. 


\section{BIOGRAPHIES}

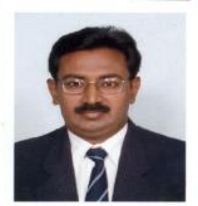

C.Christober Asir Rajan born on 1970 and received his B.E. (Distn.) degree (Electrical and Electronics) and M.E. (Distn.) degree (Power System) from the Madurai Kamaraj University, And he received his postgraduate degree in DI.S. (Distn.) from the Annamalai University, He is currently working as Associate Professor in the Electrical Engineering Department at Pondicherry Engineering College, Pondicherry, India

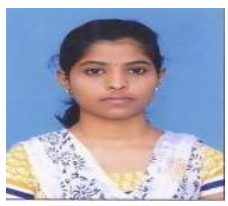

Shobana R born on 1993 and currently pursuing B.Tech final year in Electrical and Electronics Engineering department in Pondicherry Engineering College, Pondicherry, India

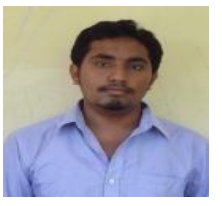

Sreekanth Reddy Y born on 1992 and currently pursuing B.Tech final year in Electrical and Electronics Engineering department in Pondicherry Engineering College, Pondicherry, India

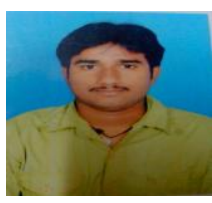

Surendra K born on 1991 and currently pursuing B.Tech final year in Electrical and Electronics Engineering department in Pondicherry Engineering College, Pondicherry, India

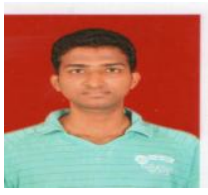

Rama Anvesh Reddy B born on 1991 and currently pursuing B.Tech final year in Electrical and Electronics Engineering department in Pondicherry Engineering College, Pondicherry, India 